\title{
The Transition to agriculture in northwestern China
}

\author{
Robert L. Bettinger ${ }^{1}$, Loukas Barton ${ }^{1}$, Peter J. Richerson ${ }^{1}$, Robert Boyd ${ }^{2}$, Wang Hui ${ }^{3}$ and Choi Won ${ }^{1}$ \\ ${ }^{1}$ University of California, Davis \\ ${ }^{2}$ University of California, Los Angeles \\ ${ }^{3}$ Gansu Province Institute of Archaeology and Cultural Relics
}

\begin{abstract}
Agriculture can evolve independently only where intensive hunter-gatherer plant use has previously evolved, and both developments are limited by two major evolutionary constraints: climatic variability and social convention. During the Pleistocene, environmental variability constrained plant productivity and therefore plant-intensive subsistence; but during the Holocene it was the hunter-gatherer social conventions that constrained the evolution of plant-based agricultural subsistence. Specifically, in places with continuous huntergatherer occupation (i.e., the Near East), social conventions prohibiting the ownership of land curtailed intensification and prolonged the transition to agriculture. In contrast, northwest China was virtually uninhabited during the Early Holocene. Here, new social orders favoring the ownership of land were free to emerge without restriction, so the transition to agriculture was rapid. Semi-permanent settlements and domesticated broomcorn millet emerged abruptly in the western Loess Plateau at Dadiwan by $7.0 \mathrm{ka}$ with no local hunter-gatherer ancestry. We propose that the intensive plant specialization required for domestication and incipient agriculture emerged first in the desert margins north of the Yellow River and migrated southwards to the more humid and fertile floodplains of the Loess Plateau west of the Liu Pan Mountains, perhaps in response to increasing aridity and climatic instability during the Early Holocene.
\end{abstract}

\section{Introduction}

Between 10.1 and $8.1 \mathrm{ka},{ }^{1}$ the hunter-gatherers of north China authored an agricultural revolution that incorporated a wide variety of species but centered on millets (Setaria italica and Panicum miliaceum), resulting in their domestication. Of the ten or so instances known worldwide in which agriculture is thought to have evolved independently (Richerson et al., 2001; Smith, 2001), this is the least understood and most problematic because it is the only one where this development cannot be traced in situ out of a long hunter-gatherer tradition. North China thus runs counter to all other known cases where agriculture developed slowly by hunter-gatherers seeking to enhance the productivity of environments with which they had become intimately familiar over many thousands of years of

${ }^{1} \mathrm{ka}$ refers to radiocarbon years, unless otherwise specified. occupation. In what follows we explore the transition to agriculture as an evolutionary problem and from that perspective detail the presently known archeological record that leads to the Dadiwan complex, the westernmost center of early millet domestication in north China.

\section{Agriculture as an Evolutionary Problem}

It is useful to introduce the origin of agriculture as an evolutionary problem by means of a metaphorical framework common in evolutionary analysis, outlined here in brief. Two basic factors set the tempo and direction of both organic and cultural evolutions (see Richerson et al., 2005). The first are factors external to the evolutionary process itself, most notably changes in the earth's physical and chemical environments, which can determine the direction and speed of evolutionary change. The second are factors internal to the evolutionary process, most notably the topography of the adaptive landscape in question - the configuration of its adaptive peaks and the width and depth of the valleys that separate them (e.g., Wright, 1932; Eldredge and Gould, 1972; Boyd and Richerson, 1992). The wider and deeper these valleys are, for example, the longer it will take to develop the innovations or combination of innovations needed to bridge from one local optimum (a "peak" on the "adaptive landscape") to another higher one. The relative importance of these factors is, of course, hotly debated. If the adaptive landscape is unimodal and relatively smooth, evolutionary change will keep time with environmental change, as externalists would have it. If it is convoluted and deeply fissured, evolutionary change may be checked by adaptive valleys and its local contours tracked in a way that has little to do with environmental change, as internalists argue. The development of agriculture is worth thinking in this way because it is so late in time, suggesting that its evolution was strongly checked by some set of external or internal factors. In comparison to the earliest representatives of the genus Homo, which appeared 2.5-2.3 million years ago, and the earliest modern humans, which appeared about 150,000 years ago, agriculture is remarkably recent, evolving independently in only a few places (e.g., the Near East and north China) during the Early Holocene, later than that in several others (e.g., Mesoamerica) and in some places not at all (e.g., California, Australia). We contend this trajectory is due to a combination of external and 


\section{Robert L. Bettinger et al.}

internal factors whose relative importance varied through time. Internal factors alone are sufficient to explain the absence of agriculture before about 80,000 years ago. Premodern Homo clearly lacked the requisite intellectual and technical capabilities, and the anatomically modern humans of the last interglacial $(130,000-80,000$ years ago) were uniformly archaic in behavior, i.e., not behaviorally modern, and likely also neither cognitively nor culturally capable of developing agriculture. After this, between 80,000 and 10,000 years ago, external factors were more important. During most of this time, and certainly by about 40,000 years ago, humans were intellectually and technically capable of developing agriculture, but Pleistocene climate and environment, in combination with the special requirements of intensive plant use and agriculture (i.e., costly preparation, harvesting and processing), prevented them from doing so. With climatic amelioration after 10,000 years ago internal factors again became dominant, this time centering on the difficulty of evolving social arrangements suitable to agriculture. Here, we are concerned first with the period 80,000-10,000 years ago, when the evolution of intensive plant-based subsistence was limited by climate; and second, with the period after 10,000 years ago, when the intensive use of plant products and ultimately the development of agriculture was limited by social organization.

\subsection{Pleistocene Climate Made Intensive Plant Use Impossible}

During the last glacial, atmospheric levels of $\mathrm{CO}_{2}$ were low, climate was very dry over large areas and probably, most important, climates were characterized by high-amplitude fluctuations on time scales of a decade or less to a millennium. Because subsistence systems specialized on plant resources are vulnerable to weather extremes and because they evolve relatively slowly ( $>1000$ years), intensive plant-based agricultural systems could not evolve during the Pleistocene. The following discussion draws heavily on our earlier work on this subject (Richerson et al., 2001), which is more detailed here than space permits.

Ice age climates varied at very short time scales. Ice core data show that during the last glacial, climate was highly variable on time scales of centuries to millennia (Dansgaard et al., 1993; Ditlevsen et al., 1996; Clark et al., 1999; GRIP 1993). Figure 1 shows data from the GRIP Greenland core.

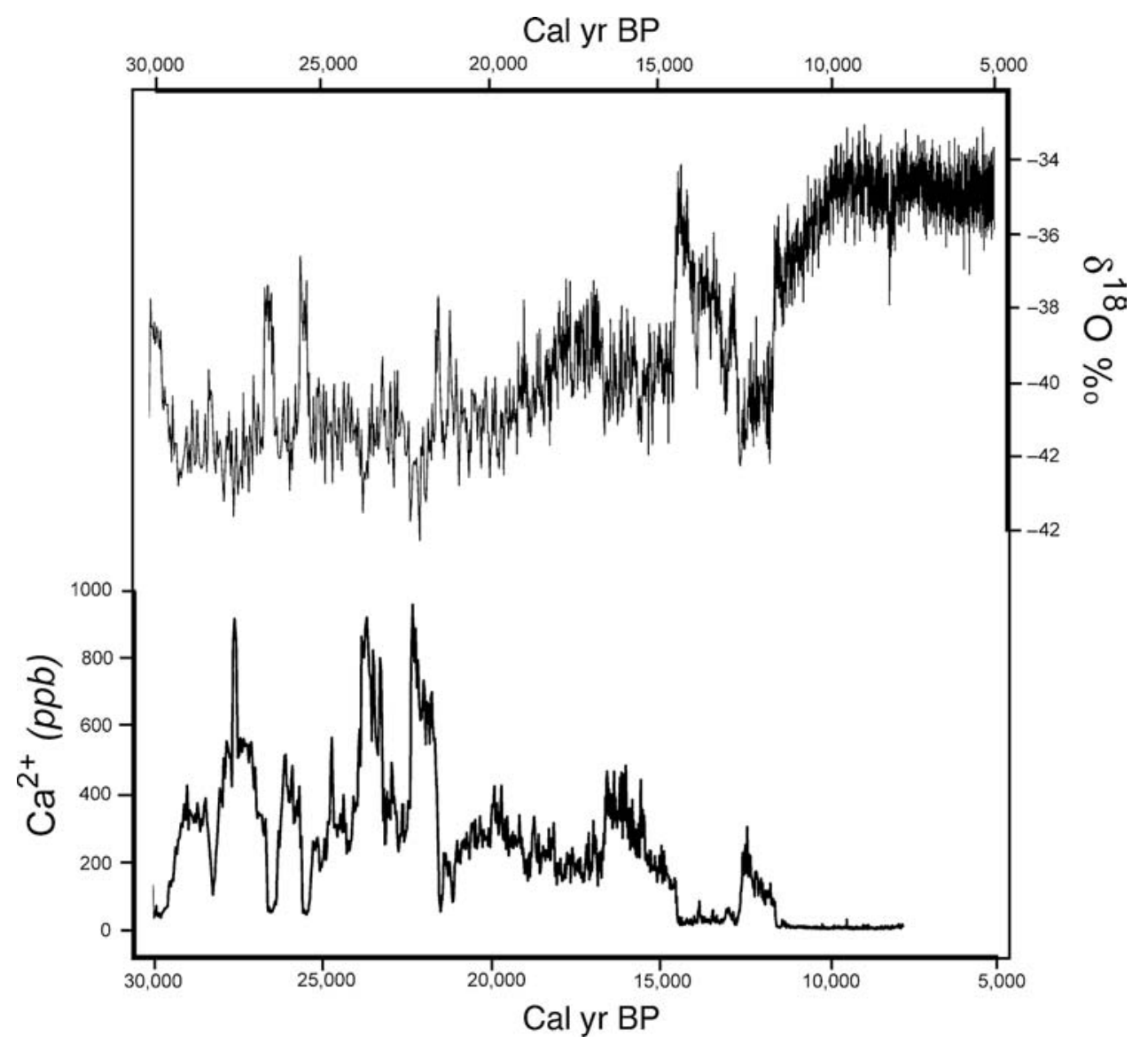

Fig. 1. Late Pleistocene-Early Holocene climate change. The upper curve represents $\Delta^{18}$ O fluctations, a generalized proxy for temperature and humidity (GRIP Members, 1993; Dansgaard et al., 1993). The lower curve plots changes in Ca ${ }^{2+}$ deposited in Greenland ice, a proxy for aridity and hemispheric dust transport (Fuhrer et al., 1999). 
The $\delta^{18} \mathrm{O}$ curve is a proxy for temperature; less negative values are warmer. The $\mathrm{Ca}^{2+}$ curve measures dust concentrations, a proxy for dust-producing arid climates. Together they show that the last glacial period was arid and extremely variable compared to the Holocene. There are sharp millennial-scale excursions in estimated temperature, atmospheric dust and greenhouse gases, right down to the limits of the highresolution records of the ice core data. The highest resolution Greenland ice records show that millennial-scale warming and cooling events often began and ended very abruptly and were often punctuated by quite large spikes of relative warmth and cold with durations of a decade or two (e.g., von Grafenstein et al., 1999 ). By the standards of the last glacial, the Holocene (the last relatively warm, ice-free 11,600 years) has been a period of very stable climate.

The dramatic climate fluctuations of the Pleistocene are also registered at lower latitudes. Hendy and Kennett (2000) report water temperature proxies from sediment cores from the Santa Barbara Basin, just offshore of central California, that show millennial- and sub-millennial-scale temperature fluctuations with an amplitude of about $8^{\circ} \mathrm{C}$ from 60 to 18 thousand years ago, compared to fluctuations of about $2^{\circ} \mathrm{C}$ in the Holocene. These millennial-scale events often show very abrupt onsets and terminations and are often punctuated by brief warm and cold spikes, as in the Greenland cores. Schulz et al. (1998) analyzed concentrations of organic matter in Arabian Sea sediment cores that show variation attesting to sharp changes in the strength of the Arabian Sea monsoon over the past 110,000 years. As with the data from Santa Barbara, the climate proxy variation in the upper part of this Arabian Sea record is well controlled by AMS ${ }^{14} \mathrm{C}$ dating and easily fits the Greenland ice millennial-scale interstadial - stadial oscillations. Furthermore, in southern Italy, Allen et al. (2000) have documented changes in the proportion of woody taxa in pollen profiles from Lago Grande di Monticchio that are dominated by large amplitude changes at the century scale and display millennial-scale variations that correlate with the Greenland record. Petersen et al. (2000) show that proxies for the tropical Atlantic hydrologic cycle have a strong millennialscale signal that likewise closely matches the Greenland pattern. Finally, the ultimate Younger Dryas millennialscale cold episode 12,900-11,600 Cal yr BP, so strongly expressed in the high-latitude ice core records, is reported in proxy records from all over the world, including southern Germany (von Grafenstein et al., 1999), the Cariaco Basin, Venezuela (Werne et al., 2000), New Zealand (Newnham and Lowe, 2000) and California (West 2001). As Cronin (1999, pp. 202-221) notes, the Younger Dryas is frequently detected in a diverse array of climate proxies from all latitudes in the Northern Hemisphere. In the Southern Hemisphere, however, proxy data often do not show a cold Younger Dryas period, although some show a similar Antarctic Cold Reversal just antedating the Northern Hemisphere Younger Dryas (Bennett et al., 2000).

Other records show millennial-scale climate fluctuations during the last glacial that cannot be convincingly correlated with the Greenland ice record. Cronin (1999, pp. 221-236) reviewed records from the deep tropical Atlantic, Western North America, Florida, China and New Zealand. Recent notable additions to this list include Southern Africa (Shi et al., 2000), the American Midwest (Dorale et al., 1998), the Himalayas (Richards et al., 2000) and northeastern Brazil (Behling et al., 2000). Clapperton (2000) details millennial-scale glacial advances and retreats from most of the American cordillera - Alaska and western North America through tropical America to the Southern Andes.

Plant productivity was also limited by lower atmospheric $\mathrm{CO}_{2}$ during the last glacial. The $\mathrm{CO}_{2}$ content of the atmosphere was about $190 \mathrm{ppm}$ during the last glacial, compared to about $250 \mathrm{ppm}$ at the beginning of the Holocene (Fig. 2). Photosynthesis on earth is $\mathrm{CO}_{2}$ limited over this range of variation (Sage 1995; Cowling and Sykes 1999). Fossil leaves from the last glacial have higher stomatal density, a feature that allows the higher rates of gas exchange needed to acquire $\mathrm{CO}_{2}$ under more limiting conditions, but also causes higher transpiration water losses per unit $\mathrm{CO}_{2}$ fixed, exacerbating the aridity characteristic of glacial times (Beerling and

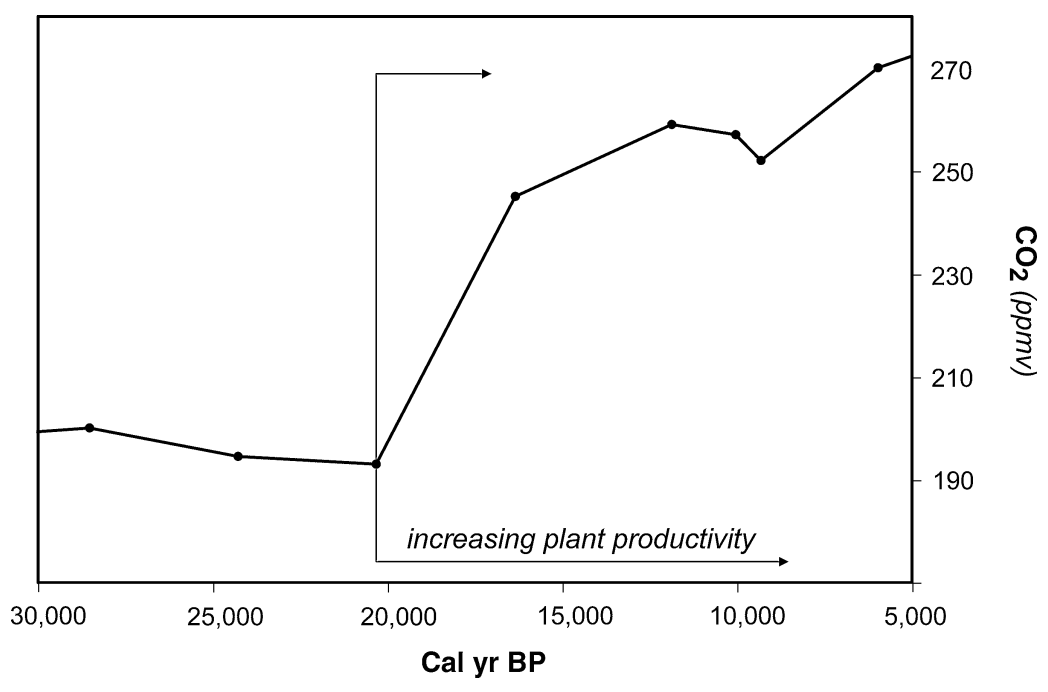

Fig. 2. Late Pleistocene-Early Holocene increases in atmospheric $\mathrm{CO}_{2}$ as recorded from Antarctic ice (Barnola et al., 1987). 


\section{Robert L. Bettinger et al.}

Woodward, 1993; see also Beerling et al., 1993). Beerling (1999) estimates the total organic carbon stored on land as a result of photosynthesis was either $33 \%$ or $60 \%$ lower at the Last Glacial Maximum than in the Holocene, depending on the model used. This low mean productivity, along with the climatically induced greater variance in productivity, would have greatly decreased both the efficiency and reliability of plantbased subsistence during the last glacial. In short, the force of Pleistocene selection favored the evolution of human behaviors associated with animal hunting but not those geared toward the use of plants. Evolution of the former was therefore rapid and varied, that of the latter more static and limited.

\subsubsection{Impacts on the Evolution of Intensive Plant Use and Agriculture}

High-frequency climate and weather variation would have made the development of intensive plant exploitation extremely difficult, and agriculture virtually impossible. Holocene millennial-scale variation was subdued in comparison to events of similar duration during the last glacial, yet it significantly affected agricultural production (Lamb 1977). Extreme years during the Little Ice Age (400$150 \mathrm{Cal} \mathrm{yr} \mathrm{BP}$ ), for example, caused notable famines (Grove, 1988). Such extremes would have been more exaggerated and frequent during last glacial times. If high-frequency climate variation at lower latitudes was roughly as great as in Greenland, an hypothetical last glacial farming system would face crippling losses in more years than not. Devastating floods, droughts, windstorms and other environmental calamities, now experienced once a century, might have occurred once a decade. Few years would be suitable for good growth of any given plant population. It is difficult to imagine intensive plant use and agriculture evolving under these conditions. Even under relatively benign Holocene conditions, intensive plant collectors and agriculturalists often barely eke by using sophisticated risk-management strategies for coping with yield variation (Winterhalder and Goland, 1997). They find storage an excellent means of meeting seasonal shortfalls, but not of coping with interannual risk, much less multi-year shortfalls (Belovsky, 1987, p. 60).

In regions that might have escaped the decadal scale variation, detected in the few truly high-resolution climate proxy records available, the evolution of sophisticated intensive plant use would still have been handicapped by the millennial-scale variation universally evident in lowerresolution records. Plant and animal populations can respond to climatic change by dramatically shifting their ranges, but late glacial climate change occurred on time scales too short for the necessary range shifts to occur. As a result, last glacial natural communities must have always been in the process of chaotic reorganization, climate varying too rapidly for communities to reach equilibrium. Pollen records from the Mediterranean and California show just how much more dynamic plant communities were during the last glacial than in the Holocene (Heusser, 1995; Allen et al., 1999).
Opportunism was probably the most important strategy for managing the risks associated with plant food use during the last glacial. Seed dormancy in annual plants spreads their risk of failure over many years, and perennials vary seed output or storage organ size substantially between years as weather dictates. In a highly variable climate, the specialization of one or a few especially promising species would be highly unlikely, because "promise" in one year or even for a decade or two would run afoul of streaks of years with little or no success. By contrast, most years are favorable for at least some species, so generalized plant exploitation systems are compatible with highly variable climates. The acorn-reliant hunter-gatherers of California, for example, used several kinds of oak, gathering less-favored species when more-favored ones failed (Baumhoff, 1963, Table 2). This worked because the annual production of individual trees is highly variable from year to year and correlated within species but independent among different species (Koenig et al., 1994). Pleistocene hunter-gatherer systems would have been even more diversified, lacking the kind of commitment to a single-resource category (such as acorns) observed in California.

The evolution of intensive plant use and agriculture is limited by internal factors that magnified the effect of shortterm late glacial climate change. It is unlikely that intensive plant exploitation systems could have tracked intense millennial- and submillennial-scale climatic variation because plant-dependent human diets do not develop that rapidly. A safe, balanced plant-rich diet takes time to evolve because plant foods are generally low in protein and often high in toxins. Other changes are required as well. Seasonal rounds have to be modified and women's customary activities given more prominence relative to men's hunting. Whether borrowed or evolved in situ, these changes tend to be slow (North and Thomas, 1973; Bettinger and Baumhoff, 1982). It is unlikely that even the sophisticated huntergatherers of the last glacial would have been able to solve the complex nutritional and behavioral problems associated with a plant-rich diet while coping with unpredictable, highamplitude climate change on time scales shorter than the equilibration time of plant migrations - shorter, indeed, than actual Holocene trajectories of plant intensification leading to agriculture. As for the record, the direct archeological evidence suggests that intensive use of the technologies that underpinned agriculture post-dates 15,000 years before present (Bettinger, 2001).

Finally, there is the effect of lower average rainfall and carbon dioxide during the last glacial. This reduced the area of the earth's surface suitable for intensive plant use and agriculture (Beerling, 1999) and thus reduced the probability of developing adaptations based on these in a given unit of time. The key effect here was on cultural transmission. Henrich (2004) argues that the ability to maintain complex cultural behaviors varies exponentially with group size, specifically the number of individuals exchanging cultural information. This means that the rate of cultural evolution will be more rapid when beneficial innovations and complex behaviors are maintained by large, interacting groups. 
Therefore, the late glacial reduction in the areas suitable for intensive plant use and agriculture, and the isolation of these areas from one another, would have reduced effective group size and increased chance losses of beneficial innovations and complex behaviors, slowing the rate at which intensive plant use and agriculture could evolve. The slowest observed rates of intensification in the Holocene (e.g., California, Argentina, Australia) failed to result in agriculture until European invasion, i.e., during an interval of just under 10,000 years. Since the fastest observed rate (e.g., Near East and north China) is about 1000 years, a coarse estimate would be that it takes something like 1000-10,000 years for agriculture to evolve under Holocene conditions. For reasons just discussed, with the reduction in areas suited to intensive plant use and agriculture, the rate would have been slower during the last glacial. This would have prevented the rapid adaptation of intensive strategies and the development of agriculture in any favorable locales or during periods that might have existed during the last glacial. Put simply, during the Pleistocene, intensive plant use and agriculture evolving on time scales greater than a millennium could not have kept pace with climate changing on millennial and sub-millennial time scales. Intensive, plant-based subsistence including, but not limited to, the harvesting, processing and cultivation of small-seeded annual grasses such as wheat, barley, maize, rice and millet was therefore impossible until the end of the Pleistocene.

\subsection{Agriculture Was Problematic During the Holocene}

Holocene climatic amelioration - the combination of $\mathrm{CO}_{2}$ enrichment, increased moisture and climatic stability - in large part removed the external factors that prevented agriculture during the Pleistocene, leaving it to evolve at a pace set by internal factors: the fissures and peaks that together define the adaptive landscape that has to be negotiated for agriculture to evolve. We have already mentioned that, in the presence of fast-paced late glacial climate change, the fissures on this landscape connected with finding the requisite suite of plants, settlement pattern, work habits, socio-political organization, etc., slowed this evolution enough to prevent the leap from generalized to plant-specialized hunting and gathering, and subsequently to agriculture. Climatic amelioration did not remove these fissures, it merely reduced the time needed to negotiate them down to something like 1000 to 10,000 years - which is not inconsiderable. We strongly suspect that technical barriers - finding productive plants and the means to process them - were the least problematic in this regard; the remarkable sophistication of ethnographic hunter-gatherers in dealing with plants suggests that the necessary technology and knowledge could develop and spread quite quickly. Developing the necessary social and political organization, on the other hand, was much more problematic. In our view, this is the principal contributor to the 1000 to 10,000 years that were required for agriculture to develop. In the remainder of this paper we detail this argument and relate it to the development of agriculture in the Dadiwan area.

\subsubsection{Low-Level Food Producers}

Smith (2001) has thoughtfully detailed the spectrum of views about the difference between hunter-gatherers and agriculturalists and the pace - fast or slow - at which agriculture evolved to replace hunting and gathering following the first experiments with food production. His concern with nomenclature is well placed and solidly grounded in a notion of process. By interposing a category of "low-level food producer" between the traditionally recognized categories of "hunter-gatherer" and "agriculturalist," Smith is not merely arguing that the transition from hunting and gathering to agriculture was sometimes slow, that groups identified as hunter-gatherers sometimes engage in a little food production and that agriculturalists sometimes fall back on hunting and gathering when their crops fail these unremarkable facts have long been known. Rather, he is asserting that the transition to agriculture is governed by a suite of relationships that make low-level food producers qualitatively different from hunter-gatherers on the one hand, and full-time agriculturalists on the other (Smith, 2001, p. 33). Smith does not elaborate on these relationships but offers some important clues, firstly, that the temporal persistence of low-level food production (typically over several millennia) suggests systems internally configured in ways that promoted stability (Smith, 2001, p. 25) and, secondly, that these systems are perhaps most reliably distinguished from systems of food procurement (hunting and gathering) by the presence of land ownership (Smith, 2001, p. 32). Smith does not overtly link these two features but there is a sensible connection on the face of it. Specifically, it is plausible that the assurance provided by land ownership might promote the stability that is said to characterize nascent food-producing systems and increase the incentive for individuals to experiment with food production, an equation that would root the origin of food production in the prior development of land ownership. Smith avoids this equation and there are problems with it.

Land ownership does not empirically segregate lowlevel food producers from hunter-gatherers cleanly enough to make the case open and shut. The generalization may hold for the hunter-gatherers of Eurasia and Africa, but not those of North America, who constitute the bulk of the ethnographically recorded hunter-gatherers living in nonmarginal environments, many of whom were land owners. Virtually all the hunter-gatherers of cismontane California, for example, owned and defended land but few, if any, engaged in food production in the usual sense, i.e., with planting or sowing. Of the seven central Great Basin huntergatherer groups that burned plots and sowed them with wild seeds, six claimed those plots as family property only temporarily (Steward, 1941, pp. 281, 314) - in keeping with the Shoshoni principle that property rights extend only to things 


\section{Robert L. Bettinger et al.}

on which work has been done (Steward, 1938, pp. 106, 253). These use rights were identical to those enjoyed by a Shoshoni couple who, because they built the house in which they lived, owned the ground on which it sat only so long as they continued to live in it. Among the groups that sowed, only the Reese River Shoshoni observed more stable, band-level, proprietary use rights - to pine nut groves and possibly wild seed plots (Steward, 1941, p. 314) - of the kind that might be seen as encouraging such experiments. The Owens Valley Paiute, on the other hand, who extended such band-level use rights even more generally - to pinyon groves, hunting and fishing territories, wild and irrigated seed plots - did not undertake experiments with reseeding (Steward, 1930; Steward, 1938, p. 53). On the face of these data, landholding is insufficient to account for food production, although it must surely promote it.

Still on the matter of the ethnographic record, it is further troubling that low-level food producers are so poorly represented in comparison to groups that make either almost all or almost none of their living by agriculture (i.e., agriculturalists and hunter-gatherers). This makes it possible to argue that the mixed economy of low-level food production is inherently unstable, or simply unattractive, relative to the pure economies of either agriculture or hunting and gathering (Hunn and Williams, 1982). The aforementioned temporal persistence of lowlevel food production in the archeological record leads Smith to discount this evident gap as an artifact of time and history. He sees in the gap the cumulative effects of agricultural expansion and the very slow gravitation of low-level food producers toward more intensive forms of agriculture throughout the Holocene, which left very few in the "middle ground." Agricultural holdings certainly expanded during the Holocene, but the considerable number of ethnographic North American hunter-gatherers dwelling in formerly agricultural lands (e.g., Southern Paiute, Apache, Cheyenne), betrays a surprising degree of agricultural retrenchment that swelled the ranks of huntergatherers without adding materially to the middle ground. Under the host of pressures that increasingly squeezed systems of all kinds as the Holocene went on, low-level food producers fared far less well than either agriculturalists or hunter-gatherers. On the whole, the ethnographic proportion of low-level food producers relative to huntergatherers and agriculturalists (i.e., low-level food producers: hunter-gatherers + agriculturalists) is commensurate with Belovsky's (Fig. 9 in Belovsky 1987) energetic map of the range of conditions (cropping rates against biomass productivity) over which each is favored. Low-level food production, as identified by both Smith and Belovsky, occupies only a sliver of the ethnographic record. The post-Pleistocene reshuffling of global environment, however, stabilized only in the Late Holocene. It is quite possible that the conditions Belovsky thinks would have promoted low-level food production were more characteristic of Early and Middle Holocene environments and that the absence of ethnographic low-level food producers is an artifact of Late Holocene environments.
The strongest empirical counter to the argument that low-level food production is unstable or narrowly attractive is archeological - the observed longevity of low-level food production in individual regional sequences. As Smith notes, the interval between the initial appearance of (low level) food production and the appearance of full blown agriculture, as denoted by settlement-subsistence systems centered around food production, is perhaps 5500 years in Mesoamerica, 4000 years in eastern North America and (arguably) 3000 years in the Near East. Longevity, however, is also a characteristic of unstable systems. As we have seen, the remarkable temporal persistence of Pleistocene hunting and gathering can be laid to an unstable environment that frustrated the perfection of technologies, behaviors and subsistence intensification needed to set the stage for food production (Richerson et al., 2001). Even where climate is stable, hunter-gatherer populations and the resources upon which they depend, hence their subsistence behaviors, are not. Human and resource populations are constantly in change, rising or falling inversely with each other, with subsistence behavior following suit, in roughly centurylong cycles (Belovsky, 1988; Winterhalder et al., 1988). In brief, the feedback between population and resources means that resources will be most abundant when human population densities are lowest and will then drop as human population grows in response to this abundance, until the human population drops in response to declining resource abundance, allowing resources to rebound. The system as a whole (humans + resources + subsistence patterns) may be dynamically stable and therefore temporally persistent. If so, it is because along the way its hunter-gatherers have continually faced and successfully responded to the dramatic cycling between extremes of resource abundance and scarcity by making major changes in subsistence, settlement and, almost surely, socio-political organization (see Barton et al., this volume). It is reasonable to think that the dynamics of low-level food production would have been broadly similar, alternately appearing and disappearing in response to this and other sources of instability.

In the most plausible scenario, the stable limit cycle regulating the relationship between population and resources causes low-level food production to appear when diet breadth expands during phases of resource depression and to disappear when diet breadth contracts during ensuing phases of resource abundance, going full-round every century or so (Belovsky, 1988, p. 351; Flannery, 1973; Winterhalder and Goland, 1993). Since the maintenance of cultural behaviors is contingent on group size (Henrich, 2004), this fluctuation in population would independently reinforce the effect of diet breadth in periodically eliminating food production from the behavioral repertoire, because population (hence, the prospect for cultural transmission) falls to its lowest when diet breadth is narrowest and least favorable to food production. Such a system might well be dynamically stable, and thus temporally persistent, but not low-level food production itself, which would phase in and out. The limits of archeological resolution are of major concern in this regard. If archeology cannot resolve the two 
phases of this cycle, at most a half-century apart, low-level food production might appear to be continuous and, by extension, stable, when it is actually discontinuous and unstable.

A system that included low-level food production but consistently cycled through a phase of pure hunting and gathering would obviously retard the development of reproductively challenged cultivars (e.g., with non-shattering rachises), because they would tend to disappear each time cultivation ceased. If, however, the compromising traits were under relatively simple genetic control that responded quickly to selective cultural modification (e.g., tough rachis wheat responding to harvest selection; Harlan, 1967), it might repeatedly develop at least often enough to appear archeologically continuous. More complex traits might actually manage to persist continuously if they were not so severely handicapped that selection removed them altogether from the landscape during the hunter-gatherer phase of the cycle. In both these cases, however, the periodic abandonment of cultivars would ultimately limit the development of traits that were beneficial to humans under cultivation but deleterious to the plants themselves when left to fend on their own in the wild. On the other hand, if population densities were high enough, and local groups within a region did not cycle in phase, even cultivars with highly deleterious traits might well develop and persist continuously by passing from group to group as demanded by resource depression.

For those archeologically long-lived systems of lowlevel food production that suggest continuous propagation of cultivars under complex genetic control (e.g., maize), this last arrangement - some sort of regional interaction sphere involving many local systems - comes closest to reconciling Smith's notion of low-level food production with the stable limit cycles that characterize any individual local system that is heavily committed to wild plants and animals. Unfortunately, this regional scenario brings us right back to where we started. Because regionally maintained cultivars are not subject to the stable limit cycles affecting local systems, their development is no more limited (hence slow moving, i.e., stable), and arguably less limited, than cultivars continuously propagated by a single local system not subject to stable limit reversals. It is unclear in either setting what prevents continual cultivar improvement, leading to an increasing investment in food production via the feedback process described long ago by Flannery (1968). Cultivar resistance to modification is one answer. However, under continual manipulation, even at moderate levels, early cultivars should have accumulated the most critical trait changes (increased seed size, durable inflorescence, etc.) they eventually developed in much shorter order than is observed. Because of this it is possible to argue that cultivar improvement was not retarded by cultivar intransigence but rather by circumstances that determined the rewards associated with their cultivation. It is in this connection that land ownership finally seems salient, firstly, because (as noted at the outset) land ownership seems critical to agricultural investment and, secondly, because land ownership and rules of private ownership in general evolve only with great difficulty and are thus likely to display the slow and uneven pattern of development said to characterize lowlevel food production.

\subsubsection{Social Barriers to Intensive Plant Use}

As one of us has outlined elsewhere (Bettinger, 1999a; Bettinger, 1999b; Bettinger, 2001), the greatest challenge to hunter-gatherer resource intensification is not technological but social - the development of rules of ownership that provide individuals the incentive to increase procurement effort. Simply put, where resources are common (i.e., public) property, individuals have little incentive to intensify their procurement effort, the proceeds from which must be split equally with others, whether or not they have invested similar levels of effort. The Hadza of Tanzania provide an apt ethnographic illustration. They have the technology to preserve meat by drying it but seldom do so, since, "To preserve and store it would be largely wasted effort, other people would simply demand meat when their own was finished and it would be wrong to refuse them" (Woodburn, 1968 , p. 53). This is likely why resource storage appears relatively late in time, far later than it should have given its technical simplicity and obvious advantages. If stored resources are public resources, the rational individual should never contribute more than the average level of effort, and preferably as little effort as possible. The proprietary use (ownership) of land is even more problematic. Ownership of stored resources is tangibly justified by the labor expended in their accumulation, as Steward (1938, p. 253) observes. Ownership of land, on the other hand, is only justified by labor previously expended - the cost of which has already been paid in full, or by labor to be expended in the future which others may be equally or even more willing to expend. Conflict, the making of public property into private property by possession and defense (e.g., Rosenberg, 1998), provides only a short-term, unstable solution. A family of fiercely defensive individuals may temporarily succeed in taking and holding land, but if population densities are relatively high and relatively mobile, and neighboring villagers regard land as public property, the land will usually revert to the public domain by force or neglect (see below).

Whatever the good (seed cache, acorn grove, hunting territory or agricultural plot), a stable system of its ownership requires a combination of owner payoffs that are large enough and a large proportion of individuals who acknowledge the right of others to own. The two are related because the benefits of ownership increase as the number of individuals acknowledging ownership rights increases (and the number individuals unwilling to acknowledge ownership commensurately decreases), diminishing the cost of splitting or defending the good. Because the costs of sharing and defense are extremely large when ownership is rare, a wellentrenched public goods system is quite stable. It is not susceptible to overthrow by individuals experimenting one at a time with ownership in groups whose other members find hoarding sinful. It can, however, be replaced via the 


\section{Robert L. Bettinger et al.}

group-level process described by Soltis et al. (1995). If ownership is a group behavior (say of a lineage or group of related lineages forming a coherent socio-political unit) and owning groups fare better than non-owning groups, non-owning groups will gradually be replaced. Since selection here acts on groups rather than individuals, the process is exceedingly slow in comparison to behavioral change driven mainly by individual rational choice, as in the spread of the horse in North America and snowmobiles in the Arctic. Group selection leading to the general practice of land ownership is unlikely to act, however, until hunting and, in particular, gathering practices become so coordinated in tune with local conditions that outsiders moving to a new area cannot get along without local instruction, forcing them to acquire the conventions that promote ownership as part of the mix (e.g., the obligation to punish poachers; McElreath et al., 2003).

The importance of such local conventions is illustrated in Fig. 3, which plots payoffs for landholders and poachers in the absence of poacher punishment (Fig. 3a), and when punishment is present (Fig. 3b). In Fig. 3a, landholder and poacher payoffs both increase with the number of landholders. As landholders increase, the number of poachers decreases, making landholding more profitable. However, the poacher payoff also increases because there is more to poach, reaching a maximum when there is only one poacher and everyone else is a landholder. Poaching is always superior to landholding, but if there are enough landholders (here more than X), the landholder payoff is greater than landholders would obtain if all of them abandoned landholding and reverted to poaching. In this sense, landholding becomes "viable." The circulation of population from locality to locality makes this landholder solution temporary and unstable; poachers would move from localities where poaching is common, and payoffs are low, to localities where landholders are common, and payoffs are high, until poaching became universal. In Fig. 3b, however, poachers are punished by landholders. Where landholders are few, punishment has a negligible effect on the poacher in comparison to its cost to the landholder; as landholding becomes more common the situation reverses because there are more punishers and fewer to punish. At some point, the poacher payoff falls below the landholder payoff. If there are any more landholders than this, landholding is favored; with any less, poaching is favored. In short, if local conventions make poaching less profitable than landholding when landholding is common, and these conventions are learned by newcomers, there will be two kinds of stable communities, landholding and poaching, and group selection will determine their differential persistence according to the disparity in their payoffs.

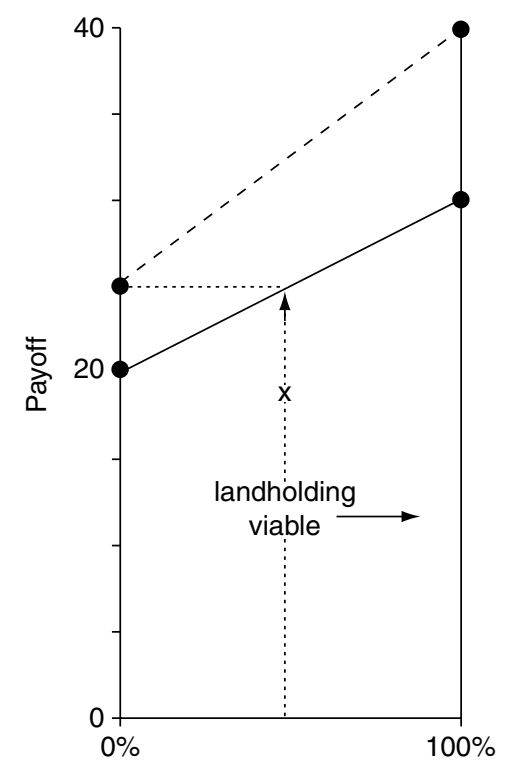

(a)

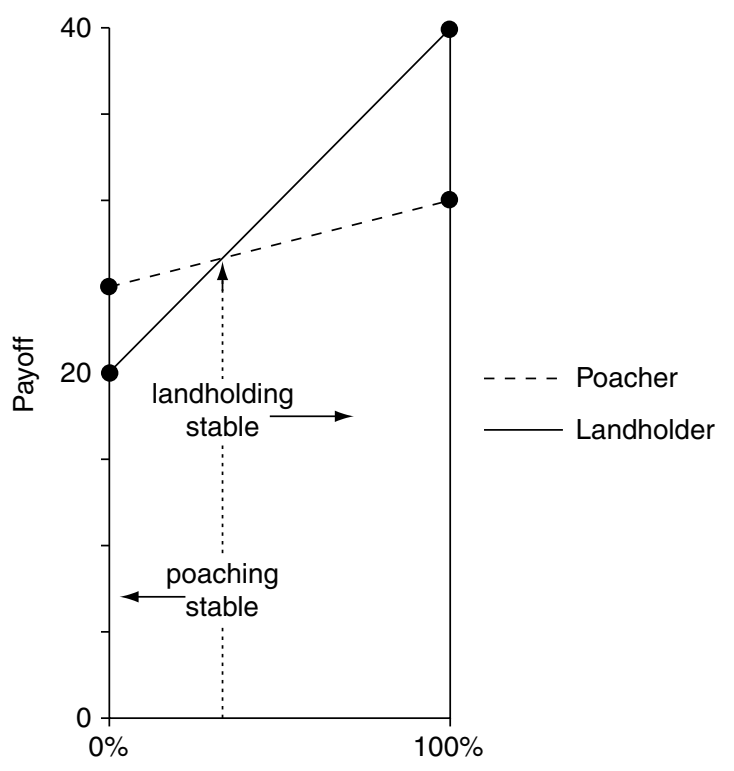

(b)

Fig. 3. Payoff structure for "landholders" and "poachers". In 3a, social conventions against poaching do not exist. Here, payoffs for individual poachers always exceed those of landholders. Landholding becomes viable (at " $X$ "), and becomes more profitable as the ratio of landholders to poachers increases. In $3 b$, the poaching payoff is weakened by punishments issued by the landholders. When landholders are few, poaching pays as the threat of punishment is minimal. However, as the proportion of landholders increases (from left to right on the $x$-axis), their payoffs also increase. This occurs because the total costs to the landholders for punishing non-landholders decreases in concert with the number of poachers. When social conventions, including punishments designed to maintain group-beneficial behavior evolve via group selection, land ownership becomes a viable and stable strategy. 
We strongly suspect that this sort of group selection ultimately accounts for the temporal persistence of lowlevel food production in many archeological records around the globe. It seems likely that the simplest form of food production, reseeding with wild strains, would have readily developed in the Early Holocene among isolated groups who brought it into play periodically, and that the more complex, productive, and selectively compromised cultivars were subsequently maintained by the same kind of groups interacting on a regional scale. The further development of these regional systems and their cultivars, however, required social conventions governing the use of land, which proceeded through the slow group selection process just described. In this way, hunter-gatherer population growth associated with Early Holocene climatic amelioration would have thwarted agricultural development, prolonging the pattern Smith has labeled as low-level food production.

The limits on agricultural development would obviously be greatest in landscapes that had been occupied and filled by increasingly sophisticated hunter-gatherers for thousands of years well back into the Pleistocene, before any form of food production began. By contrast, the greatest potential for a rapid transition to agriculture would have been in places without long Pleistocene hunter-gatherer histories. In an empty landscape, colonizing groups of low-level food producers might establish proprietary land use practices that encouraged agricultural investment without having to contest these practices with an existing hunter-gatherer population that regarded all land as public domain. Here, the processes of colonization and rapid growth, rather than group selection, would apply. Such situations, however, are rare because the places most favorable to food production are almost always the places most favorable to hunting and gathering in general, and intensive hunting and gathering in particular. Nevertheless, this appears to be the case in north China.

\section{Late Pleistocene - Early Holocene Prehistory of North China}

The archeology of the Late Pleistocene and Early Holocene is less well documented in north China than in the Near East, Mesoamerica or South America, but is not the mystery it was just two decades ago, when the late K.C. Chang's (1986) final treatment of ancient China appeared. Since then, one of the most significant published contributions available to western scholars has been the synthetic treatment of hunter-gatherer and early agricultural sites, assemblages and radiocarbon dates compiled by Lu (1999). Her work underscored the importance of bridging the temporal gap that has long frustrated attempts to establish a convincing link between the youngest known Late Pleistocene Paleolithic assemblages and the oldest known Middle Neolithic examples of early millet agriculture, traditionally divided into three geographical complexes: Peiligang, Cishan and Dadiwan (An, 1988; Fig. 1; 1991). More recently, other roughly contemporaneous, early agricultural complexes have been identified at Houli, along the eastern-most reaches of the Yellow River, and at Xinle and Xinglongwa in northeast China (Guo, 1995; Underhill, 1997; Yan, 1999; Shelach, 2000). General outlines of Chinese culture history classify these early agricultural complexes as "Middle Neolithic," reserving the "Early Neolithic" designation for a suspected, but largely unidentified transitional period between foraging and farming (Cohen, 1998; Yan, 1999; Cohen, 2002).

The material evidence used to justify the "agricultural" classification of specific sites varies widely. In some cases, the designation is based on the presence of domesticated plant or animal taxa; in others, it is based simply on the presence of ceramics or architectural features that resemble those found at sites with known domesticates (see $\mathrm{Lu}$, 1999). Recent efforts have focused on establishing the degree of agricultural subsistence in Middle and Late Neolithic China on the basis of stable isotope chemistry (Zhang et al., 2003; Pechenkina et al., 2005) and skeletal biometry and paleopathology (Jackes and Gao, 1994; Smith, 2005). At this point, archeological evaluations of the degree or intensity of agricultural subsistence during the Neolithic are just beginning in China. However, with few exceptions, the Middle Neolithic culture areas of north China are viewed as sedentary or semi-sedentary agricultural complexes with domesticated plants and animals along with other markers of intensive plant use such as pottery and ground-stone. None are considered strictly hunters and gatherers.

The first two classically Middle Neolithic complexes of north China, Peiligang and Cishan, are lowland centers $(<650$ m.a.s.1.), sitting on the middle reach of the Yellow River. Together with Houli, they are often seen as being connected to Late Pleistocene lithic assemblages 200-300 km to the east (e.g., Xiachuan and Xueguan; Chen, 1984; Chen and Olsen, 1990; Lu 1999) or Early Holocene sites $300-500 \mathrm{~km}$ to the north (e.g., Nanzhuangtou; Guo and $\mathrm{Li}, 2002)$. Noting the co-occurrence of millet and rice remains at Jiahu, a site belonging to the Peiligang cultural horizon, some authors propose that millet domestication is an outgrowth of earlier, rice-centered agricultural systems that originate well south of the Yellow River drainage (Cohen, 2002; Bellwood, 2005). While this remains an attractive, tentative hypothesis for the origin of millet-based agricultural systems located along the middle reaches of the Yellow River and the north China Plain, it does little to explain the near synchronous appearance of millet-based systems at Dadiwan (700-800 km northwest of Jiahu) or at Xinle and perhaps Xinglongwa (1200-1300 km to the northeast).

In contrast to the lowland agricultural centers of the central and eastern Yellow River drainage, Dadiwan is an upland center, on the upper Wei River in the southwestern Loess Plateau (CPAM 1981; CPAM 1982; Zhang and Zhou, 1985). The Dadiwan-type site, the oldest of the complex (sometimes termed Laoguantai), sits at an elevation of about 1800 masl, on the uppermost Wei, more than $700 \mathrm{~km}$ west of Peiligang and Cishan.

The difference in elevation and their geographical separation makes it improbable that the Dadiwan complex 
92 Robert L. Bettinger et al.

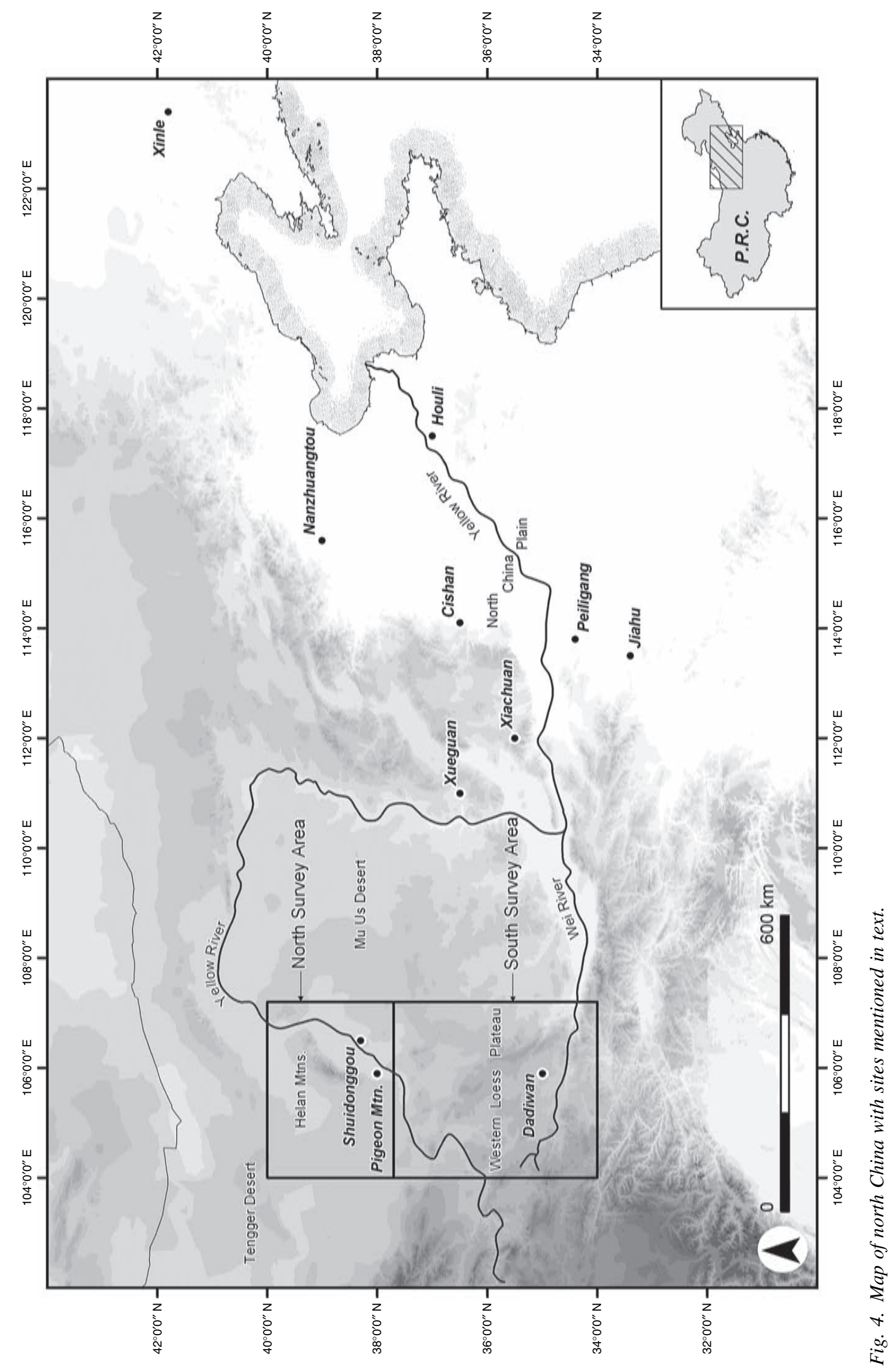


shares its roots with the assemblages believed potentially ancestral to Cishan and Peiligang. Upland Dadiwan is much more closely connected to the Late Pleistocene and Early Holocene upland complexes of the upper Yellow River, in the southern Mongolian Plateau, 300-400 km to the north, than to more distant Late Pleistocene and Early Holocene sites like Xueguan $(490 \mathrm{~km})$, Xiachuan $(560 \mathrm{~km})$ and Nanzhuangtou $(970 \mathrm{~km})$. The cultivars, too, were probably different. Dadiwan is the probable location of the domestication of broomcorn millet (Panicum miliaceum; Underhill, 1997, p. 121; Yan, 1992, p. 117; Cohen, 1998, p. 22; Shelach, 2000, p. 380), which ripens faster and is more tolerant of cold and drought than foxtail millet (Setaria italica; Baltensperger, 1996), which is more suited to the warmer, moister north China Plain.

\subsection{Prehistory of the Upper Yellow River - Southwestern Loess Plateau}

Our team of Chinese and US scholars has been pursuing this connection since 1989 in a large study area anchored on the Dadiwan-type site (Fig. 4; Bettinger et al., 1990; Bettinger et al., 1994). The northern part of this area is outside the Loess Plateau. Here, expansive sandy deserts (Tengger Desert, Mu Us Desert) run right to the edge of the bottomlands of the upper Yellow River, which flows first east and then north along the eastern front of the north - south trending Helan Mountains. South of the Yellow River, patches of sandy desert increasingly give way to the hilly, rolling topography of the Loess Plateau, rising to the watershed between the Upper Yellow and Upper Wei River drainages, about $50 \mathrm{~km}$ north of the Dadiwan site. Data acquired in our research at the major sites of Shuidonggou and Pigeon Mountain, and by others, are sufficient to capture the patterns of change in technology, climate, and adaptation in the northern part of this area beginning about 41,000 years ago that were likely seminal to the development of agriculture in the southern part. Distinct lithic technologies are the signature of three Late Pleistocene Early Holocene time periods - Shuidonggou, Helan, and Tengger - that frame this discussion.

\subsubsection{Shuidonggou Period (41.0-24.0 ka)}

The Shuidonggou period is characterized by a distinctive Levallois-like, flat-faced core technology directed toward blade production that is part of the early Upper Paleolithic (EUP) techno-complex of northeast Asia, roughly 40.0-25.0 ka (Brantingham et al., 2001; Brantingham et al., 2004). Dates from the type site (Shuidonggou) in the study area indicate a relatively late fluorescence, from 29.0 to $24.0 \mathrm{ka}$ (Madsen et al., 2001). However, a minimum-limiting date of $41,070 \pm 890{ }^{14} \mathrm{C}$ yr BP (Beta 161632) on carbonate encrusting a flake from the only other known north China EUP assemblage (also in the study area) suggests that the Shuidonggou period is essentially conterminous with the larger northeast Asian EUP techno-complex. Three cultural deposits exposed in the southern part of our study area (Guyuan 3, 25,228 $\pm 766{ }^{14} \mathrm{C}$ yr BP, CAMS 93161\&2; Tong Xin 3, 25, $030 \pm 80{ }^{14} \mathrm{C}$ yr BP, CAMS 93167\&8; Tong Xin 8, 24, $760 \pm 220{ }^{14} \mathrm{C}$ yr BP, CAMS 93169) are coeval in time with Shuidonggou and belong to the Tong Xin facies of the Chinese EUP (see Barton et al., this volume). The nearest of these is more than $190 \mathrm{~km}$ and the farthest more than $260 \mathrm{~km}$, south of Shuidonggou, suggesting the EUP population of north China was more widely distributed, and perhaps larger, than previously thought (see also Gao et al., 2004).

Shuidonggou period settlement patterns are poorly understood, but the blade-oriented technology suggests the use of relatively sophisticated grooved or socketed tools fitted with replaceable end-blade or multiple side-blade insets, hinting at a relatively specialized and residentially mobile adaptation likely oriented to the large herbivores (wooly rhinoceros, Coelodonta antiquitatis; horse, Equus przewalskyi; ass, E. hemionus; antelope, Spiroceros kiakhtensis; and gazelle, Gazella sp.) represented in the Shuidonggou faunal assemblage (Madsen et al., 2001, pp. 712, 714). Such specialization might account for the failure of the north China EUP to persist into and across the cold, dry LGM, perhaps owing to the diminishing abundance of the large vertebrates that seem to have been important. Goebel (1999) observes a similar contraction of the Siberian EUP during the LGM. Whatever its ultimate fate, there is no post-LGM expression of the EUP anywhere in north China. Indeed north of the Yellow River there is a gap in the archeological record until the beginning of the Helan period at $12.7 \mathrm{ka}$, which is characterized by a technology quite unlike the EUP. However, hunter-gatherer groups continued to occupy the Loess Plateau, south of the Yellow River, throughout the LGM (see Barton et al., this volume).

\subsubsection{Helan Period (12.7-11.6 ka)}

In contrast to the blade-oriented EUP, Helan period lithic technology is dominated by a diverse array of spheroids, flake tools, scrapers, gouges and a series of triangular, ovate and bi-pointed bifaces (Helan points) for which the period is named (Madsen et al., 1995; Madsen et al., 1996; Elston et al., 1997; Zhang 1999). We term this technology macrolithic - characterized by large tools reduced by coarse percussion, generally using grainy, tough and locally available quartzites and metavolcanics. Millingstones indicate some use of small seeds. Chipped and ground adzes and axes may be present, more surely so in the following Tengger period.

The diversity of tool forms and prominence of those suitable for making and maintaining digging sticks, grinding seeds and pulping fiber, roots and small game, imply the use of a broader range of species, and smaller ones, and a greater use of plants than in the Shuidonggou period. This, and the substantial size of Helan assemblages, suggests an adaptation less residentially mobile than during the 


\section{Robert L. Bettinger et al.}

Shuidonggou period. Sites are characteristically located on the margins of expansive dune fields in proximity to uplands, striking a locational compromise between these distinctly different resource opportunities. This provided immediate access to the waterfowl, small game, plants and herding ungulates associated with interdunal ponds and wetlands, and logistical access to more solitary ungulates and a different range of plants in the sand-free piedmonts and uplands. Dune ponds and wetlands are most productive during the summer-fall wet season and progressively less attractive with desiccation during the winter-spring dry season, when residence probably shifted to piedmonts and uplands where springs provided water. In comparison to those on dune margins, Helan upland sites are fewer and their assemblages generally larger and more diverse, suggesting the use of especially favored locations as relatively permanent base camps during this lean dry season. The more numerous dune margin sites, on the other hand, argue that dune plants and animals were much preferred, attracting the bulk of Helan settlement during the season when resources were most abundant (wet season) during a time period of relative resource abundance. Milling equipment suggests that seeds were at least a minor dunefield attraction during this period of climatic amelioration, which ended with an abrupt and rapid return to the cold-dry glacial environments that characterized the Younger Dryas (Madsen et al., 1998). Lake levels dropped, and interdunal lakes, ponds and wetlands frequently dried up and filled with wind-blown sand. Our Tengger period broadly coincides with the Younger Dryas.

\subsubsection{Tengger Period (11.6-10.1 ka)}

Technology changed with climate in the Tengger period: macrolithic technology diminished in relation to microlithic technology: soft-hammer percussion and pressure-flaked thumbnail end-scrapers, bifaces, arrowheads, flake tools, microblades, retouched microblades and pebble microcores. There was a parallel shift in raw material use, from quartzites and metavolcanics, to cryptocrystalline cherts and chalcedonies. Most of these microlithic elements are present in the preceding Helan period. But while the range of chipped stone tool types is about the same overall, Tengger assemblages are more evenly balanced owing to the greater investment in an array of sophisticated technologies (e.g., microblades) that suggest resource specialization, much as in the blade-dominated Shuidonggou period, but targeting more and smaller species.

Sampling error and preservation probably explain why the Tengger assemblage lacks milling tools and is richer in faunal remains than the Helan assemblage. Nevertheless, these differences are consistent with our view that subsistence narrowed significantly during the Younger Dryas - with hunting increasing in importance relative to gathering - and that this is behind the increase in microblades. Dune-field resources, including waterfowl, small game and ungulates, clearly became more important. Microblades, microcores and other microlithic technology indicate continued use of dune margin camps in the wet season and upland base camps in the dry season, when resources were scarce. The many more sites scattered throughout dune-field interiors feature microlithic technology exclusively, however, attesting to a more intensive pattern of wet season dune use that began in the Tengger period and extended well into the Holocene. The sheer abundance of these dune interior sites makes it fairly clear that dune resources were preferred during seasons of relative abundance, as in the Helan period.

\subsubsection{Early Holocene (10.1 ka)}

The Helan period extends through the first summer monsoon episode of the Holocene (10.1 ka), a warm-wet interval of interdunal lake and marsh refilling that abruptly terminated the Younger Dryas (Madsen et al., 2003). Helan groups seem to have responded by further intensifying dune procurement using a technology increasingly given to microblades in an increasingly dune-centered settlement pattern. The growing opportunities for plant procurement were likely also turned to advantage. The wild form of broomcorn millet (Panicum miliaceum) was probably used as a seasonal food and perhaps stored to prolong occupation of interdunal camps with access to more highly valued resources. It is difficult to be certain about much of this, however, because our Early Holocene archeological record ends here. No archeological site anywhere in our northern study area has produced a radiocarbon date that falls between 10.1 and $7.9 \mathrm{ka}$. In the southern study area the record picks up still later, at the early agricultural site of Dadiwan, at $7.0 \mathrm{ka}\left(6,950 \pm 90,{ }^{14} \mathrm{C}\right.$ yr BP, BK80025; Institute of Archaeology 1991), $340 \mathrm{~km}$ south of the dune and upland Helan sites of the upper Yellow River.

\subsection{The Gap in the Record}

The absence of Early Holocene dates in the northern part of our study area is probably a function of our project design; we did not date likely Early Holocene sites. The same cannot be said for the southern part of the study area. The dearth of known Early Holocene sites here does not reflect either sampling error or lack of effort. The Gansu Institute of Archaeology has records for 3007 sites that together present 3601 cultural components in the broader Dadiwan region $\left(102.4^{\circ}-108.7^{\circ} \mathrm{E}, 33.5^{\circ}-37.2^{\circ} \mathrm{N}\right.$; Table 1). Of these, none is Early Neolithic. This, and the dearth of earlier Paleolithic and Late Paleolithic sites (just 19 in total, all single component), makes it most improbable that the agricultural Dadiwan complex (i.e., Middle Neolithic) emerged from a local hunter-gatherer base. That Dadiwan sites, on the other side of this temporal gap, are so rare (three in total), and at the same time all multicomponent (with Yangshao and later elements), attests instead to a trajectory of continuous agricultural development whose local roots are no deeper than Dadiwan itself. The absence of human occupation in the Dadiwan region during 
Table 1. Temporal distribution of components in Gansu Institute Survey.

\begin{tabular}{llllll}
\hline $\begin{array}{l}\text { Paleolithic/Late } \\
\text { Paleolithic }\end{array}$ & Early Neolithic & $\begin{array}{l}\text { Middle Neolithic } \\
\text { (Dadiwan) } \\
(\text { Cal yr вP) }\end{array}$ & Early Yangshao & $\begin{array}{l}\text { Middle/Late } \\
\text { Yangshao }\end{array}$ & Qijia \\
\hline$>10,000$ & $10,000-8000$ & $8000-7000$ & $7000-6000$ & $6000-5000$ & $5000-4000$ \\
19 & 0 & 3 & 62 & 1542 & 1975 \\
\hline
\end{tabular}

the Early Holocene is hard to explain, but wetland-swamp deposits indicating the onset of conditions that would have been highly attractive to hunter-gatherers are a recurrent signature in stratigraphic sections $7.0-5.5 \mathrm{ka}$ throughout the western Chinese Loess Plateau, denoting a warm-wet climax within what Feng et al. (2004) term the Mid-Holocene Megahumid event. This mountainous region would have been much less attractive in the absence of these extensive wetlands.

The Dadiwan regional chronology thus repeats the familiar north China pattern, noted long ago (e.g., An, 1988, Fig. 1) and commented upon by Lu (1999): the interval $10.0-8.0 \mathrm{ka}$ is remarkably under-represented and the "Early Neolithic" of north China's culture history essentially non-existent. Radiocarbon data are somewhat deceiving in this sense: of the 118 reliable dates we have been able to assemble for all of north China that fall between 14.0 and $6.0 \mathrm{ka}$, no fewer than $11(9.3 \%)$ are between 10.0 and $8.0 \mathrm{ka}$. While this is still less than the frequency of dates falling in this interval in Near East (264, $53 \%)$ and Japan $(21,25 \%)$ assembled for rough comparison, a temporal gap is not clearly apparent (Table 2, 3). However, 10 of these 11 north China dates are from just one site, Nanzhuangtou (Guo and Li, 2002). And, as our sites on the Upper Yellow River stand in relation to Dadi-

Table 2. Distribution of representative radiocarbon dates for the period 14 - 6 ka from north china, the Near East and Japan (see Table 3 for sources).

\begin{tabular}{lccccccccc}
\hline & $14-13 \mathrm{ka}$ & $13-12 \mathrm{ka}$ & $12-11 \mathrm{ka}$ & $11-10 \mathrm{ka}$ & $10-9 \mathrm{ka}$ & $9-8 \mathrm{ka}$ & $8-7 \mathrm{ka}$ & $7-6 \mathrm{ka}$ & Total \\
\hline North China. & 0.05 & 0.05 & 0.05 & 0.12 & 0.07 & 0.03 & 0.28 & 0.36 & 118 \\
Near East. & 0.04 & 0.05 & 0.06 & 0.18 & 0.19 & 0.34 & 0.11 & 0.02 & 494 \\
Japan & 0.04 & 0.04 & 0.01 & 0.06 & 0.08 & 0.17 & 0.25 & 0.35 & 83 \\
\hline
\end{tabular}

Table 3. Sources for Radiocarbon Data Referenced in Table 2 and Fig. 5.

\begin{tabular}{lll}
\hline No. of dates & Reference & Region/culture/site \\
\hline 24 & IA-CASS, 1991 & China \\
1 & IA-CASS, 1997 & China \\
1 & IA-CASS, 2001 & China \\
2 & Anderson, 2004 & Xinle \\
1 & Bettinger et al., 2005a & Peng Yang 4 \\
1 & Bettinger et al., 2005b & Dadiwan \\
5 & Elston et al., 1997 & Pigeon Mountain \\
1 & Fu, 2003 & Qingtoushan \\
19 & Li et al., 2003:34 & Jiahu \\
1 & Lu, 1998 & Daxingtun \\
8 & Lu, 1999: Table 4(1) & North China preagricultural \\
36 & Lu, 1999: Table 4(7) & North China Neolithic \\
1 & Madsen et al., 1998 & Pigeon Mountain \\
1 & Madsen et al., 2003 & Jilantai \\
1 & RDL-BD, 1994 & Nanzhuangtou \\
10 & Shelach, 2000:371 & Xinglongwa, NE China \\
5 & Yuan et al., 1998 & Shizitan \\
129 & Byrd, 1994 & Near East \\
365 & Kuijt and Bar-Yosef, 1994 & Near East \\
4 & Serizawa, 1974 & Japan \\
79 & Keally and Muto, 1982 & Japan \\
\hline
\end{tabular}




\section{Robert L. Bettinger et al.}

wan, $340 \mathrm{~km}$ to the south, so does Nanzhaungtou in relation to the early centers of millet agriculture on the north China Plain to the south, Houli $(277 \mathrm{~km})$, Cishan $(305 \mathrm{~km})$ and Peiligang $(536 \mathrm{~km})$ : Nanzhaungtou articulates with these sites in time but not space. The situation in north China is better appreciated when our sample of radiocarbon dates $(n=118)$ are plotted in degrees latitude north (Fig. 5). Here the temporo-spatial separation between the sites representing the early centers of north China agriculture (Houli, Cishan, Peiligang, Xinle, and Dadiwan) and their potential ancestors, is clearly apparent. In none of these cases is there a credible evidence for the development of agriculture from a local base.

\section{Middle Holocene Population Movement from the Upper Yellow River}

Although we suspect the process leading to agriculture at Cishan and Peiligang may have been similar, our major concern is with the Dadiwan complex. Given the dearth of Late Pleistocene-Early Holocene sites representing an intensive hunter-gatherer adaptation from which it might be locally derived, the most likely explanation for appearance of broomcorn millet agriculture at Dadiwan is that it was developed by intensive hunter-gatherers moving south, out of the deserts along the Upper Yellow River, in the northern part of our study area. While the evidence suggests a generally benign climate in these deserts during the Early
Holocene (Shi et al., 2002), with summer monsoon episodes at 9.3 and $8.0 \mathrm{ka}$ (in addition to the one at $10.1 \mathrm{ka}$ previously mentioned; Madsen et al., 2003), these were interleaved with droughts (see Wünnemann et al., this volume) and it is clear that the overall trend was toward longer dry spells and shorter wet ones, leading to a deep Mid-Holocene drought from 6.0 to $4.4 \mathrm{ka}$ (Chen et al., 2003). In the most plausible scenario, former upper Yellow River desert dwellers, already familiar with wild broomcorn millet, probably drifted progressively southward with each drought, increasingly attracted by the highly productive wetland/swamp environments that became established in the river bottoms of the western Chinese Loess Plateau during the climax of the Mid-Holocene Megahumid (Feng et al., 2004). It is significant in this regard that the Megahumid component of the stratigraphic section at Dadiwan (7.5-5.0 ka; Fig. 6 in Feng et al., 2004) is characterized not by wetland/swamp deposits but rather by alternating couplets of wetland/ swamp and fluvial deposits attesting to frequent, but shortterm, flooding that would have produced disturbed mud flat microhabitats highly suited to agriculture, which likely explains why agriculture first appeared at Dadiwan specifically, at $7.0 \mathrm{ka}$. Since Dadiwan is agricultural from the start, however, these groups must have become lowlevel food producers before they arrived at Dadiwan, but after they left the upper Yellow River, where evidence of early agriculture is evidently lacking. It is quite thinkable that as these groups drifted further south into the unfamiliar Chinese Loess Plateau, they may have intensified their use

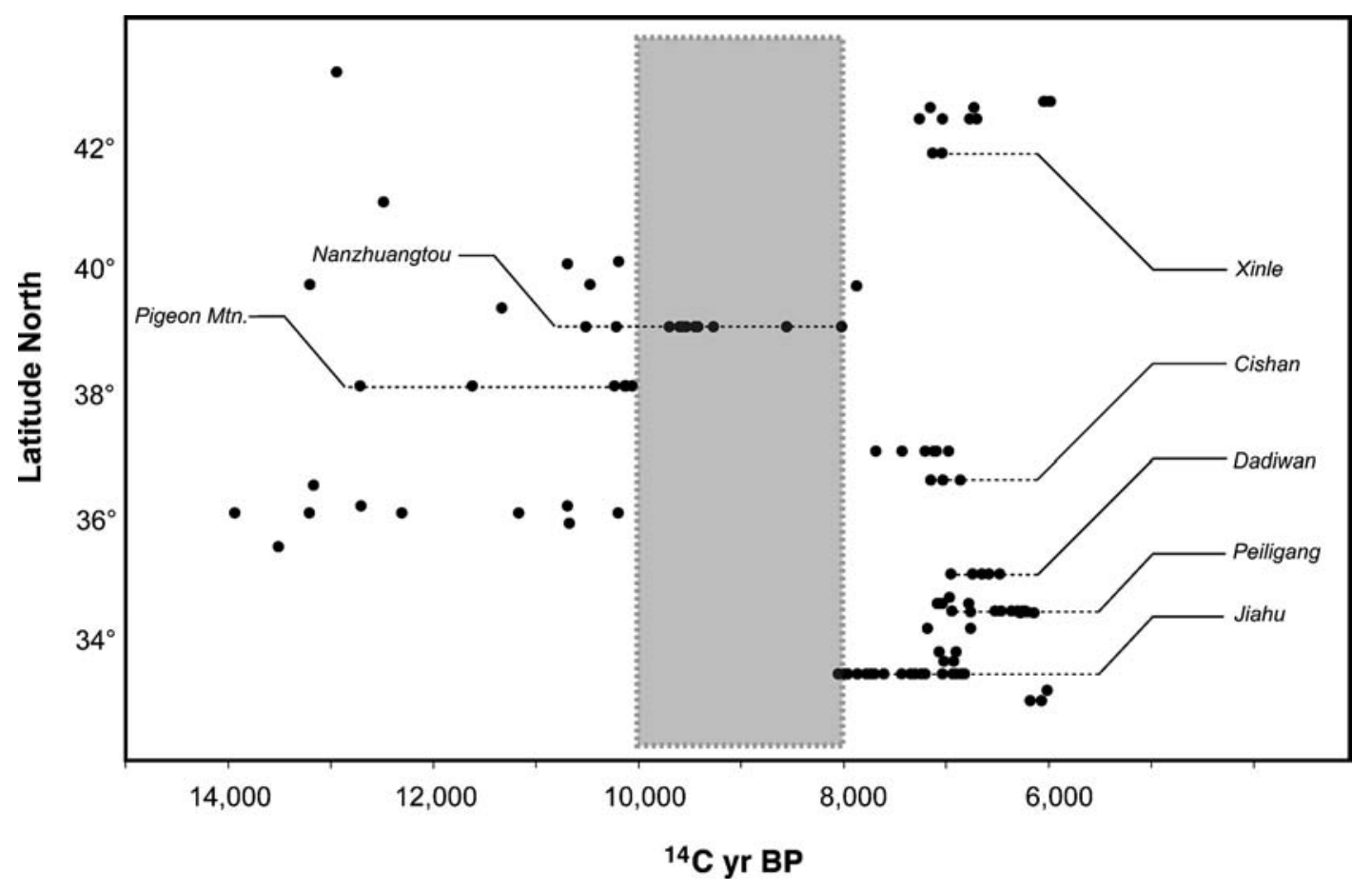

Fig. 5. Radiocarbon dates $(n=118)$ from north China between 14,000 and $6000{ }^{14} \mathrm{C}$ yr BP plotted by latitude. Callouts on the right identify early agricultural sites, those on the left identify preagricultural sites. The shaded area depicts the archeological hiatus over much of north China between 10,000 and 8,000 ${ }^{14} \mathrm{C}$ yr BP (see Table 3 for sources). 
of the fast ripening (60-90 days; Baltensperger, 1996) broomcorn millet in a small way, casually sowing it around fall-winter settlements, mainly as a "catch crop," when wild resources were observed to be unpromising. The output of this low-level form of food production would have qualitatively increased simply as a consequence of its introduction to the muddy flood plains around Dadiwan, in short order transforming a minor fallback food into a reliable crop.

Despite this improved productivity, it is probably best to regard the initial phase of Dadiwan (Dadiwan I) as representing a form of what Smith (2001) terms low-level food production: Dadiwan I components are not only rare, they are characteristically thin, suggesting small and fairly mobile populations. In contrast to low-level food production elsewhere, however, this pattern is comparatively short lived. Without having to contend with a long established population of hunter-gatherers resistant to the establishment of territories, the holding of private agricultural plots and the hoarding of food, the Dadiwan system rapidly intensified and expanded. In scarcely one thousand years, it produced Early Yanshao settlements like Banpo and Jiangzhai, which were clearly not inhabited by low-level food producers. The initial component at Jiangzhai (Jackes and Gao,1994), for example, represents an organized, intensive agricultural village, with five groupings of houses (120 in all) laid out around a $4000 \mathrm{~m}^{2}$ central plaza, a full complement of hearths $(n>200)$, storage pits $(n>300)$, animal pens, a separate kiln area and a cemetery with three distinct sections (each with about 26 urns and 50 primary burials, displaying a high frequency of violence; Jackes and Gao, 1994).

\section{Conclusion}

The emergence of millet agriculture in northwest China differs in two ways from the trajectory of early agriculture observed elsewhere around the world, notably Mesoamerica and the Near East. First, millet agriculture did not emerge from a local hunter-gatherer base, but was rather introduced by groups migrating into areas that were either uninhabited or only sparsely occupied. Second, early millet agriculture expanded and intensified quite rapidly, with only a short interval of low-level production. In places like the Near East, on the other hand, agriculture emerges from intensive patterns of hunting and gathering that cap long histories of in situ development and is characterized by an initial stage of low-level food production lasting four or five thousand years. It is unlikely these differences are coincidental. What these data suggest is that when early agriculture develops in situ, and has to compete with an existing hunter-gatherer base, it expands slowly, as in the Near East; when it develops or appears in places where it does not have to compete with an existing hunter-gatherer base, it expands rapidly, as in the Dadiwan to Banpo transition. This, in turn, suggests that it is hunter-gatherer social conventions precluding the ownership of land and hoarding of resources that hinder the intensification of low-level food production. Where these are absent, agriculture expands rapidly. Where they are present, agriculture can intensify only by the slow process of group selection, in which groups that preclude landholding (hence intensive agriculture) are replaced, one by one, by agricultural groups that permit it. It is the slow pace of group selection that explains the long intervals of low-level food production.

\section{Acknowledgments}

The research reported here would not have been possible without grants generously provided by the University of California Pacific Rim Research Program and US National Science Foundation BCS-Archaeology, Program NSF 01-153 "High-Risk Survey for the Earliest Agriculture in North China," Grant Number 0222742. This work represents the collaborative effort of US and PRC scholars, including several not listed as authors: Robert G. Elston, David B. Madsen, Charles G. Oviatt, David E. Rhode; Fahu Chen, Yan Zhu and Duxue Ji (Lanzhou), Kan Zhong, Cheng Xu, Jinzhen Li and Rui Yang (Ningxia); Yuozhu You and Xing Gao (IVPP, Beijing); Zhangwei Li (Shanxi); and Haizhou Ma (Qinghai). We would like to thank Rowan Flad for his thorough efforts to improve the clarity of an earlier version of this paper.

\section{References}

Allen, J.R., Brandt, A., Hubberten, H.-W., Huntley, B., Keller, J., Kraml, M., Mackensen, A., Mingram, J., Negendank, J.F., Nowaczyk, N.R., Oberhansli, H., Watts, W.A., Wulf, S., Zolitschka, B., 1999. Rapid Environmental Changes in Southern Europe During the Last Glacial Period. Nature 400, 740-743.

Allen, J.R.M., Watts, W.A., Huntley B., 2000. Weichselian Palyostratigraphy, Palaeovegetation and Palaeoenvironment: The Record from Lago Grande di Monticchio, Southern Italy. Quaternary International 73/74, 91-110.

Allen, J.R.M., Watts, W.A., McGee, E., Huntley B., 2002. Holocene environmental variability - the record from Lago Grande di Monticchio, Italy. Quaternary International 88(1), 69-80.

An, Z., 1988. Archaeological Research on Neolithic China. Current Anthropology 29(5), 753-759.

An, Z., 1991. Radiocarbon Dating and the Prehistoric Archaeology of China. World Archaeology 23(2), 193-200.

Anderson, R., 2004. Applying Anticipated Mobility to Sedentism Analysis of Pre-Hongshan Cultures in NorthEast China. Eras 6, 1-19.

Baltensperger, D., D. 1996. Foxtail and proso millet. In: Janick J. (Ed.), Progress in New Crops. Alexandria, VA, ASHS Press, pp. 182-190.

Barnola, J.M., Raynaud, D., Korotkevich, Y.S., Loris, C., 1987. Vostok Ice Core Provides 160,000-Year Record of Atmospheric CO2. Nature (329), 408-414. ftp://ftp. ncdc. noaa. gov/pub/data/paleo/icecore/antarctica/vostok/co2.txt.

Baumhoff, M.A. 1963. Ecological Determinants of Aboriginal California Populations. Berkeley, University of California Press. 


\section{Robert L. Bettinger et al.}

Beerling, D.J., 1999. New Estimates of Carbon Transfer to Terrestrial Ecosystems Between the Last Glacial Maximum and the Holocene. Terra Nova 11, 162-167.

Beerling, D.J., Chaloner, W.G., Huntley, B., Peason, J.A., Tooley, M.J., 1993. Stomatal Density Responds to the Glacial Cycle of Environmental Change. Proceedings of the Royal Society of London B 251, 133-138.

Beerling, D.J., Woodward, F.I., 1993. Ecophysiological Responses of Plants to the Global Environmental Change Since the Last Glacial Maximum. New Phytologist 125, 641-648.

Behling, H., Arz, H.W., Pätzold, J., Wefer, G., 2000. Late Quaternary Vegetation and Climate Dynamics in Northeastern Brazil, Inferences From Marine Core Geob 3104-1. Quaternary Science Reviews 19, 981-994.

Bellwood, P.S. 2005. The First Farmers: The Origins of Agricultural Societies. Malden, MA, Blackwell.

Belovsky, G.E., 1987. Hunter-Gatherer Foraging: A Linear Programming Approach. Journal of Anthropological Archaeology 6, 29-76.

Belovsky, G.E., 1988. An Optimal Foraging-Based Model of Hunter-Gatherer Population Dynamics. Journal of Anthropological Archaeology 7, 329-372.

Bennett, K.D., Haberle, S.G., Lumley, S.H., 2000. The Last Glacial-Holocene Transition in Southern Chile. Science 290, 325-328.

Bettinger, R.L. 1999a. From Traveler to Processor: Regional trajectories of hunter-gatherer sedentism in the InyoMono region, California. In: Billman B. R., Feinman G. M. (Eds.), Settlement Pattern Studies in the Americas: Fifty Years Since Viru. Washington D.C, Smithsonian Institution Press, pp. 39-55.

Bettinger, R.L. 1999b. What happened in the Medithernal. In: Beck C. (Ed.), Models for the Millennium: Great Basin Anthropology Today. Salt Lake City, University of Utah Press, pp. 62-74.

Bettinger, R.L. 2001. Holocene hunter-gatherers. In: Feinman G. M., Price T. D. (Eds.), Archaeology at the Millennium: A Sourcebook. New York, Kluwer Academic/ Plenum Publishers, pp. 137-195.

Bettinger, R. L., Barton, L., Elston, R. G., 2005a. Report on 2002 archaeological fieldwork in Gansu and Ningxia Provinces, PRC. Prepared for the U.S. National Science Foundation BCS-Archaeology, Program NSF 01-153 "High-Risk Survey For The Earliest Agriculture In North China" Grant Number 0222742. http://www.anthro.ucdavis.edu/card/usprc/publications.htm.

Bettinger, R.L., Barton, L., Brantingham, P.J., Elston, R.G., 2005b. Report on 2004 Archaeological Fieldwork at the Dadiwan Site, Shao Dian Village, Gansu Province, PRC. Prepared for the Pacific Rim Research Program. http:// www.anthro.ucdavis.edu/card/usprc/publications.htm.

Bettinger, R.L., Baumhoff, M.A., 1982. The Numic Spread: Great Basin Cultures in Competition. American Antiquity 47(3), 485-503.

Bettinger, R.L., Elston, R.G., Madsen, D.B., Brantingham, P.J., Barton, L., Oviatt, C.G., Wang, H., 2003. Late
Paleolithic Occupation of North China. Poster presented at the XVI INQUA Congress, Reno, NV.

Bettinger, R.L., Elston, R.G., Madsen, D.B., Li, Z., You, Y., 1990. Transitional Paleolithic-Neolithic Settlement and Subsistence in Alashan League, Western Inner Mongolia, People's Republic of China. Current Research in the Pleistocene 7, 1-3.

Bettinger, R.L., Madsen, D.B., Elston, R.G., 1994. Prehistoric Settlement Categories and Settlement Systems in the Alashan Desert of Inner Mongolia, PRC. Journal of Anthropological Archaeology 13, 74-101.

Boyd, R., Richerson, P.J. 1992. How microevolutionary processes give rise to history. In: Nitecki M. H., Nitecki D. V. (Eds.), History and Evolution. Albany, SUNY Press, pp. 178-209.

Brantingham, J.P., Krivoshapkin, A.I., Li, J., Tserendagva, Y., 2001. The Initial Upper Paleolithic in Northeast Asia. Current Anthropology 42(5), 735-747.

Brantingham, P.J., Gao, X., Madsen, D.B., Bettinger, R.L., Elston, R.G. 2004. He Initial Upper Paleolithic at Shuidonggou, Northwestern China. In: Brantingham P. J., Kuhn S. L., Kerry K. W. (Eds.), The Early Upper Paleolithic Beyond Western Europe. Berkeley, London, University of California Press, pp. 223-241.

Byrd, B.F., 1994. Late Quaternary Hunter-Gatherer Complexes in the Levant Between 20,000 and 10,000 BP. In: Bar-Yosef, O., Kra, R. S. (Eds.), Late Quaternary Chronology and Paleoclimates of the Eastern Mediterranean. Tucson, Radiocarbon, University of Arizona, pp. 205-226.

Chang, K.C., 1986. The Archaeology of Ancient China, 4th ed. New Haven, Yale University Press.

Chen, C., 1984. The Microlithic of China. Journal of Anthropological Archaeology 3, 79-115.

Chen, C., Olsen, J.W., 1990. China at the Last Glacial Maximum. In: Soffer O., Gamble C. (Eds.), The World at 18000 BP, Vol. 1: High Latitudes. London, Unwin Hyman, pp. 276-291.

Chen, F., Wu, W., Holmes, J.A., Madsen, D.B., Zhu, Y., Jin, M., Oviatt, C.G., 2003. A Mid-Holocene Drought Interval as Evidenced by Lake Desiccation in the Alashan Plateau, Inner Mongolia, China. Chinese Science Bulletin 48(14), 1401-1410.

Clapperton, C., 2000. Interhemispheric Synchroneity of Marine Isotope Stage 2 Glacial Fluctuations Along the American Cordilleras Transect. Journal of Quaternary Science 15, 435-468.

Clark, P.U., Alley, R.B., Pollard, D., 1999. Northern Hemisphere Ice-Sheet Influences on Global Climate Change. Science 286, 1104-1111.

Cohen, D.J., 1998. The Origins of Domesticated Cereals and the Pleistocene-Holocene Transition in East Asia. the Review of Archaeology 19(2), 22-29.

Cohen, D.J. 2002. New Perspectives on the Transition to Agriculture in China. In: Yasuda Y. (Ed.), The Origins of Pottery and Agriculture. New Delhi, Roli Books, pp. 217-227.

Cowling, S.A., Sykes, M.T., 1999. Physiological Significance of Low Atmospheric CO2 for Plant-Climate Interactions. Quaternary Research 52, 237-242. 
CPAM. Provincial Museum of Gansu, the Dadiwan Excavation Group 1981. Gansu Qin'an Dadiwan xinshiqi shidai jiaoqi yizhi (Early Neolithic remains at Dadiwan, Qin' an Xian, Gansu). Wenwu (Cultural Relics) 4, 1-8. In Chinese.

CPAM. Dadiwan Excavation Group 1982. Qin'an Dadiwan 1980 nian fajue jianbao (A brief report on the excavation of Dadiwan in Qin'an during the 1980 season). Kaogu yu Wenwu (Archaeology and Relics) 2, 1-8. In Chinese.

Cronin, T.M. 1999. Principles of Paleoclimatology. New York, Columbia University Press.

Dansgaard, W., Johnsen, S.J., Clausen, H.B., Dahljensen, D., Gundestrup, N.S., Hammer, C.U., Hvidberg, C.S., Steffensen, J.P., Sveinbjornsdottir, A.E., Jouzel, J., Bond, G., 1993. Evidence for General Instability of Past Climate From a 250-Kyr Ice-Core Record. Nature 364(6434), 218-220. ftp://ftp.ngdc.noaa.gov/paleo/icecore/greenland/summit/grip/isotopes/gripd18o.txt

Ditlevsen, P.D., Svensmark, H., Johnsen, S., 1996. Contrasting Atmospheric and Climate Dynamics of the LastGlacial and Holocene Periods. Nature 379, 810-812.

Dorale, J.A., Edwards, R.L., Ito, E., González, L.A., 1998. Climate and Vegetation History of the Midcontinent From 75 to 25 Ka: A Speleothem Record From Crivice Cave, Missouri, USA. Science 282, 1871-1874.

Eldredge, N., Gould, S.J., 1972. Punctuated Equilibria: An Alternative to Phyletic Gradualism. In: Schopf, T. J. M. (Ed.), Models in Paleobiology. San Francisco, Freeman, pp. 82-115.

Elston, R.G., Xu, C., Madsen, D.B., Zhong, K., Bettinger, R.L., Li, J., Brantingham, P.J., Wang, H., Yu, J., 1997. New Dates for the North China Mesolithic. Antiquity 71(274), 985-994.

Feng, Z., An, C., Tang, L., Jull, T.A., 2004. Stratigraphic Evidence of a Megahumid Climate Between 10,000 and 4000 Years B. P. In the Western Part of the Chinese Loess Plateau. Global and Planetary Change 43, 145-155.

Flannery, K.V. 1968. Archaeological systems theory and early Mesoamerica. In: Meggers B. J. (Ed.), Anthropological Archeology in the Americas. Washington, D. C, Anthropological Society of Washington, pp. 67-87.

Flannery, K.V., 1973. The Origins of Agriculture. Annual Review of Anthropology 2, 271-310.

Fu, R., 2003. Shilun Woguo Dongbeidiqu Qiushiqi Shidaiwanqi wenhua ji zhuyao tezheng (Paleolithic cultures and their characteristics in northeast China). Paper presented at the International symposium commemorating the 80th anniversary of the discovery of Shuidonggou, Yinchuan, Ningxia Province, P.R.C. In Chinese.

Fuhrer, K., Wolff, E.W., Johnsen, S.J., 1999. Timescales for Dust Variability in the Greenland Ice Core Project (GRIP) Ice Core in the Last 100,000 Years. Journal of Geophysical Research-Atmospheres 104(D24), 31043-31052.

Gao, X., Pei, S., Wang, H., Zhong, K., 2004. Ningxia Jiushiqi Kaogu Diaocha Baogao (A Report on Paleolithic Reconnaissance in Ningxia, North China). Renleixuebao (Acta Anthropologica Sinica) 23(4), 307-325. In Chinese.
G.R.I.P Members, 1993. Climate Instability During the Last Interglacial Period Recorded in the GRIP Ice Core. Nature 364, 203-207. ftp://ftp.ngdc.noaa.gov/paleo/icecore/ greenland/summit/grip/isotopes/gripd18o.txt

Grove, J.M. 1988. The Little Ice Age. London, Methuen.

Guo, D. 1995. Hongshan and related cultures. In: Nelson S. M. (Ed.), Archaeology of Northeast China: Beyond the Great Wall. London, New York, Routledge, pp. 21-64.

Guo, R., Li, J. 2002. The Nanzhuangtou and Hutouliang sites: Exploring the beginnings of agriculture and pottery in North China. In: Yasuda Y. (Ed.), The Origins of Pottery and Agriculture. New Delhi, Roli Books, pp. 193-204.

Harlan, J.R., 1967. A Wild Wheat Harvest in Turkey. Archaeology 20, 197-201.

Hendy, I.L., Kennett, J.P., 2000. Dansgaard-Oeschger Cycles and the California Current System: Plaktonic Forminiferal Response to Rapid Climate Change in Santa Barbara Basin Ocean Drilling Program Hole 893a. Paleoceanography $15,30-42$.

Henrich, J., 2004. Demography and Cultural Evolution: How Adaptive Cultural Processes Can Produce Maladaptive Losses - the Tasmanian Case. American Antiquity 69(2), 197-214.

Heusser, L.E., 1995. Pollen stratigraphy and paleoecologic interpretation of the 160-K.Y. record from the Santa Barbara Basin; Hole 893A. Proceedings of the Ocean Drilling Program, Scientific Results 146, 265-277.

Hunn, E.S., Williams, N.M. 1982. Introduction. In: Williams N. M., Hunn E. S. (Eds.), Resource Managers: North American and Australian Hunter-Gatherers. Boulder, CO, Westview Press, pp. 1-16.

IA-CASS. (Institute of Archaeology, Chinese Academy of Social Science) 1991. Zhongguo Kaoguxue Zhong Tanshisi Niandai Shujiji 1965-1991 (Radiocarbon Dates in Chinese Archaeology, 1965-1991). Cultural Relics Publishing House, Beijing. In Chinese.

IA-CASS. (Institute of Archaeology, Chinese Academy of Social Science) 1997. Radiocarbon dating report 24. Kaogu (Archaeology) 7, 35-38. In Chinese.

IA-CASS. (Institute of Archaeology, Chinese Academy of Social Science) 2001. Radiocarbon dating report 27. Kaogu (Archaeology) 7, 82-86. In Chinese.

Jackes, M., Gao, Q., 1994. Jiangzhai and BanPo (Shaanxi, PRC): New ideas from old bones. Paper presented at the From the Jomon to Star Carr Conference, 4-8 Sept 1994, Cambridge, Durham.

Keally, C.T., Muto, Y., 1982. Jomon Jidai No Nendai (Jomon Period Dates). Jomon Bunka No Kenkyu I: Jomon-Jin to Sono Kankyo (Studies of the Jomon Culture, Vol. I: The Jomon People and the Surrounding Environment), 246-275. In Japanese.

Koenig, W.D., Mumme, R.L., Carmen, W.J., Stanback, M.T., 1994. Acorn Production by Oaks in Central Coastal California: Variation Within and Among Years. Ecology 75(1), 99-109.

Kuijt, I., Bar-Yosef, O. 1994. Radiocarbon chronology for the Levantine Neolithic: Observations and data. 
In: Bar-Yosef, O., Kra, R. S. (Eds.), Late Quaternary Chronology and Paleoclimates of the Eastern Mediterranean. Tucson, Radiocarbon, University of Arizona, pp. 227-246.

Li, X., Harbottle, G., Zhang, J., Wang, C., 2003. The Earliest Writing? Sign Use in the Seventh Millennium BC at Jiahu, Henan Province, China. Antiquity 77(295), 31-44.

Lu, T.L.D., 1998. The Microblade Tradition in China: Regional Chronologies and Significance in the Transition to Neolithic. Asian Perspectives 37(1), 84-112.

Lu, T.L.D. 1999. The Transition From Foraging to Farming and the Origin of Agriculture in China. BAR International Series. Oxford, British Archaeological Reports, 774.

Madsen, D.B., Chen, F., Oviatt, C.G., Zhu, Y., Brantingham, P.J., Elston, R.G., Bettinger, R.L., 2003. Late Pleistocene/Holocene Wetland Events Recorded in Southeast Tengger Desert Lake Sediments, NW China. Chinese Science Bulletin 48(14), 1423-1429.

Madsen, D.B., Elston, R.G., Bettinger, R.L., 1995. Hua Bei Zhong Bu Jiushiqi Wan Qi Zhi Xinshiqi Zao Qi Ju Luo Xin Tai De Bian Hua (Late Paleolithic-Early Neolithic Settlement Assemblage Changes in North Central China). Kaogu (Archaeology) 7, 1013-1027. In Chinese.

Madsen, D.B., Elston, R.G., Bettinger, R.L., Xu, C., Zhong, K., 1996. Settlement Patterns Reflected in Assemblages From the Pleistocene/Holocene Transition of North Central China. Journal of Archaeological Science 23, 217-231.

Madsen, D.B., Li, J., Brantingham, P.J., Gao, X., Elston, R.G., Bettinger, R.L., 2001. Dating Shuidonggou and the Upper Paleolithic Blade Industry in North China. Antiquity $77,706-16$.

Madsen, D.B., Li, J., Elston, R.G., Xu, C., Bettinger, R.L., Geng, K., Brantingham, P.J., Zhong, K., 1998. The Loess/ Paelosol Record and the Nature of the Youger Dryas Climate in Central China. Geoarchaeology 13(8), 847869.

McElreath, R., Boyd, R., Richerson, P.J., 2003. Shared Norms and the Evolution of Ethnic Markers. Current Anthropology 44(1), 122-129.

Newnham, R.M., Lowe, D.J., 2000. Fine-Resolution Pollen Record of Late-Glacial Climate Reversal From New Zealand. Geology 28, 759-762.

North, D.C., Thomas, R.P. 1973. The Rise of the Western World: A New Economic History. Cambridge, Cambridge University Press.

Pechenkina, E.A., Ambrose, S.H., Ma, X., Benfer,. R.A., Jr. 2005. Reconstructing Northern Chinese Neolithic Subsistence Practices by Isotopic Analysis. Journal of Archaeological Science 32, 176-1189.

Petersen, L.C., Haug, G.H., Haugen, K.A., Röhl, U., 2000. Rapid Changes in the Hydrologic Cycle of the Tropical Atlantic During the Last Glacial. Science 290, 1947-1951.

RDL-BD. (Radiocarbon Dating Laboratory, Department of Archaeology, Peking University) 1994. Tanshisi Niandai Ceding Baogao 9 (Radiocarbon dating report 9). Wenwu (Cultural Relics) 4, 89-95.
Richards, B.W., Owen, L.A., Rhodes, E.J., 2000. Timing of Late Quaternary Glaciations in the Himalayas of Northern Pakistan. Journal of Quaternary Science 15, 283-297.

Richerson, P.J., Bettinger, R.L., Boyd, R. 2005. Evolution on a restless planet: Were environmental variability, environmental change major drivers of human evolution. In: Wuketits, F. M., Ayala, F. J. (Eds.), Handbook of Evolution, Volume 2: The Evolution of Living Systems (Including Hominids). Weinheim, Wiley-VCH Verlag GmbH \& Co, KGaA, pp. 223-242.

Richerson, P.J., Boyd, R., Bettinger, R.L., 2001. Was Agriculture Impossible During the Pleistocene but Mandatory During the Holocene? A Climate Change Hypothesis. American Antiquity 66(3), 387-411.

Rosenberg, M., 1998. Cheating at Musical Chairs: Territoriality and Sedentism in an Evolutionary Context. Current Anthropology 39(5), 653-680.

Sage, R.F., 1995. Was Low Atmospheric CO2 During the Pleistocene a Limiting Factor for the Origin of Agriculture. Global Change Biology 1, 93-100.

Schulz, H., von Rad, E., Erlenkeuser, H., 1998. Correlation Between Arabian Sea and Greenland Climate Oscillations of the Past 110,000 Years. Nature 393, 54-57.

Serizawa, C., 1974. Kodishi Hakkutsu I. Saiko no Kariyudotachi: Kyusekki Jidai (Discovery of Ancient History, Vol. I. The Oldest Hunters: Paleolithic Age). Kodansha, Toyko. In Japanese.

Shelach, G., 2000. The Earliest Neolithic Cultures of Northeast China: Recent Discoveries and New Perspectives on the Beginning of Agriculture. Journal of World Prehistory 14(4), 363-413.

Shi, N., Dupont, L.M., Beug, H.-J., Schneider, R., 2000. Correlation Between Vegetation in Southwestern Africa and Oceanic Upwelling in the Past 21,000 Years. Quaternary Research 54, 72-80.

Shi, Q., Chen, F., Zhu, Y., Madsen, D.B., 2002. Lake Evolution of the Terminal Area of Shiyang River Drainage in Arid China Since the Last Glaciation. Quaternary International 93-94, 31-43.

Smith, B.D., 2001. Low-Level Food Production. Journal of Archaeological Research 9(1), 1-43.

Smith, B.L., 2005. Diet, Health, and Lifestyle in Neolithic North China, Unpublished Ph.D Dissertation on file at the Department of Anthropology, Harvard University.

Soltis, J., Boyd, R., Richerson, P.J., 1995. Can Group-Functional Behaviors Evolve by Cultural Group Selection. Current Anthropology 36(3), 473-494.

Steward, J.H., 1930. Irrigation Without Agriculture. Papers of the Michigan Academy of Science, Arts, and Letters 12, 149-156.

Steward, J.H. 1938. Basin-Plateau Aboriginal Sociopolitical Groups. Bureau of American Ethnology Bulletin 120. Washingon, D. C, Bureau of American Ethnology.

Steward, J.H. 1941. Culture Element Distributions, XIII: Nevada Shoshone. University of California Anthropological Records, vol. 4. Berkeley, University of California, pp. 209-259. 
Underhill, A.P., 1997. Current Issues in Chinese Neolithic Archaeology. Journal of World Prehistory 11(2), 103-160. von Grafenstein, U., Erlenkeuser, H., Brauer, A., Jouzel, J., Johnsen, S.J., 1999. A Mid-European Decadal IsotopeClimate Record From 15,500 to 5000 Years B. P. Science 284, 1654-1657.

Werne, J.P., Hollander, D.J., Lyons, T.W., Peterson, L.C., 2000. Climate-Induced Variations in Productivity and Planktonic Ecosystem Structure From the Younger Dryas to Holocene in the Cariaco Basin, Venezuela. Paleoceanography 15, 19-29.

West, G.J., 2001. Pollen analysis of late Pleistocene-Holocene sediments from Core CL-73-5, Clear Lake, Lake County, California: A terrestrial record of California's cismontane vegetation and climate change inclusive of the Younger Dryas Event. Proceedings of the 17th Annual Pacific climate Workshop, Interagency Ecological Program for the San Francisco Estuary Technical Report 67, 91-106.

Winterhalder, B., Baillargeon, W., Cappelletto, F., Daniel, J., Prescott, I.R., 1988. The Population Ecology of HunterGatherers and Their Prey. Journal of Anthropological Archaeology 7, 289-328.

Winterhalder, B., Goland, C., 1993. On Population, Foraging Efficiency, and Plant Domestication. Current Anthropology 34(5), 710-715.

Winterhalder, B., Goland, C. 1997. An evolutionary ecology perspective on diet choice, risk, and plant domestication. In: Gremillion K. J. (Ed.), People, Plants, and Landscapes:
Studies in Paleoethnobotany. Tuscaloosa, University of Alabama Press, pp. 67-87.

Woodburn, J. 1968. An introduction to Hadza ecology. In: Lee R. B., DeVore I. (Eds.), Man the Hunter Chicago, Aldine, pp. 49-55.

Wright, S., 1932. The Roles of Mutation, Inbreeding, Cross Breeding and Selection in Evolution. Proceedings of the 6th International Congress on Genetics 1, 356-366.

Yan, W. 1992. Origins of agriculture and animal husbandry in China. In: Aikens C. M., Song N. R. (Eds.), Pacific Northeast Asia in Prehistory: Hunter-Fisher-Gatherers, Farmers, and Sociopolitical Elites. Pullman, Washington, Washington State University Press, pp. 113-123.

Yan, W., 1999. Neolithic Settlements in China: Latest Finds and Research. Journal of East Asian Archaeology 1, 131-147.

Zhang, P., Zhou, G., 1985. The connections between the "First Phase" at Dadiwan and other cultures. In: Dien A. E., Riegel, J. K., Price N. T. (Eds.), Chinese Archaeological Abstracts, 2: Prehistoric to Western Zhou. UCLA, Los Angeles, Institute of Archaeology, pp. 253-258.

Zhang, S., 1999. A Study of Stone Artifacts Found at the Xiaokouzi Prehistoric Site. Renleixuebao (Acta Anthropologica Sinica) 18, 81-101. In Chinese.

Zhang, X., Wang, J., Xian, Z., Chou, S., 2003. Gurenlei Shiwu Jiegou Yanjiu (Study on the Diet of Ancient People). Kaogu (Archaeology) 2, 62-75. In Chinese. 